\title{
Fascia lata composite graft for right ventricular outflow tract and pulmonary artery reconstruction
}

\author{
Surgical technique
}

\author{
MARIAN I. IONESCU and RADU C. DEAC \\ Department of Cardiothoracic Surgery, The General Infirmary at Leeds and Leeds University
}

\begin{abstract}
Because there is no 'ideal' method for the complete correction of some of the more complex congenital cardiac abnormalities, a technique of making a composite graft of autologous fascia lata has been developed.

Three types of grafts are described, all of them being based on the same general principle. The composite graft comprises a conduit, which serves to enlarge or reconstruct the outflow tract of the right ventricle and the main pulmonary artery, and an inner valve attached inside it, which provides the conduit with a one-way flow mechanism.

The technique of preparing these composite grafts is outlined and the surgical implantation of the grafts in the right ventricular outflow is described.

Since November 1969, fascia lata composite grafts have been used in 18 patients with a variety of complex congenital heart malformations with very good early results.
\end{abstract}

Open heart surgery for congenital cardiac malformations has progressed rapidly during the past 15 years. Continuous advance in surgical technique produced better results in some congenital diseases and made possible operative correction of other complex abnormalities which until recently were not amenable to surgical repair.

Since the first total correction of a Fallot's tetralogy (Lillehei, Cohen, Warden, Read, Aust, DeWall, and Varco, 1955) there has been a continuous endeavour for improvement. Lillehei, Cohen, Warden, and Varco (1956) used a right ventricular outflow tract patch to relieve the obstruction and advocated insertion of a monocusp valve to prevent the occurrence of pulmonary regurgitation after total correction (Lillehei, Levy, Adams, and Anderson, 1964).

Ross and Somerville (1966) used an aortic homograft for right ventricular outflow tract reconstruction in a Fallot's tetralogy with pulmonary atresia. Marchand (1967) and Weldon, Rowe, and Gott (1968) also employed aortic homografts in the repair of Fallot's tetralogy. Fuller, Marchand, Zion, and Zwi (1966) reconstructed a grossly regurgitant pulmonary valve with a pulmonary homograft.

Surgical correction of more complex congenital heart abnormalities was attempted recently. The use of tubes without valves, or tubes containing prosthetic valves (Cooley and Hallman, 1966), was unsatisfactory. On the other hand, methods using valve grafts have proved successful in the reconstruction of the right ventricular outflow tract and pulmonary artery and valve.

Rastelli, Titus, and McGoon (1967) described a technique for total correction of truncus arteriosus with an aortic homograft, and McGoon, Rastelli, and Ongley (1968) and Wallace, Rastelli, Ongley, Titus, and McGoon (1969) applied it successfully in several cases. For the anatomical correction of complete transposition of the great arteries, Rastelli (1969) developed a new technique, again by using an aortic homograft, and employed it successfully in two patients (Rastelli, McGoon, and Wallace, 1969; Rastelli, Wallace, and Ongley, 1969).

For patients with congenital pulmonary atresia and ventricular septal defect Kouchoukos, Barcia, Bargeron, and Kirklin (1970) also used a conduit between the right ventricle and the pulmonary arteries. A tube of pericardium or Tefion without a valve and an aortic homograft with its valve or a Dacron tube with an aortic homograft valve within it were used. At the present time these authors prefer the last.

The conventional intracardiac repair of Fallot's tetralogy gives excellent results in the majority of cases. There are, however, cases in which a com- 
plete anatomical correction cannot be obtained. Residual obstruction and surgically created pulmonary regurgitation by patch enlargement of the pulmonary annulus are but two of the drawbacks of the conventional technique for 'total correction'.

There are also situations in which the repair is difficult or impossible due to aberrant coronary arteries, severe pulmonary hypoplasia or atresia, or to the abnormal anatomy as in truncus arteriosus.

Prosthetic valves used in the outflow tract of the right ventricle have been unsuccessful because they are unsuited for this particular anatomical position.

It is self evident that simple conduits without valves inside are functionally inadequate for pulmonary artery and valve reconstruction. The aortic homograft (ascending aorta with its valve), although superior to the previous two methods, has several drawbacks.

The process of collection, sterilization, and storage is laborious and time consuming. The longterm fate of preserved homografts is uncertain, mainly because they are used as nonviable structures. Early calcification of the aortic wall of the graft, when used for pulmonary reconstruction, was reported (Bowman, 1969; McGoon, 1969, personal communication; Wallace, 1969; Weldon $\stackrel{\vec{F}}{\vec{\rho}}$ et al., 1968). Regurgitation through the homo- $\frac{\sigma}{0}$ graft valve also occurred (Marchand, 1967; 음 Weldon et al., 1968), presumably due to distortion of the graft when curved over the wall of the $\mathbb{\otimes}$ right ventricle.

To obviate the drawbacks of these techniques, $\infty$ and based on our previous experience with fascia $\vec{\circ}$ lata heart valve replacement (Ionescu and Ross, $\overrightarrow{\vec{\omega}}$ 1969; Ionescu, Ross, Deac, Grimshaw, Taylor, $\stackrel{\circ}{\circ}$ Whitaker, and Wooler, 1970), we made an auto- $\vec{x}$ logous fascia lata composite graft (a conduit containing a three-cusp valve) and used it in the re- or construction of the right ventricular outflow tract and pulmonary artery and valve in 18 patients with $\vec{v}$ good immediate results.

This paper describes the technique of making $\stackrel{3}{\overrightarrow{3}}$ composite fascial grafts. The operative technique $\breve{ }_{-}$ of inserting these grafts and the clinical experience so far are briefly mentioned.

\section{PREPARATION OF FASCIA LATA COMPOSITE GRAFTS}

The composite graft comprises a conduit which serves to enlarge or reconstruct the outflow tract of the right ventricle and the main pulmonary $\frac{D}{D}$ artery and an inner valve attached inside it which $\triangle$ provides the conduit with a one-way flow mechan- $\overrightarrow{\overrightarrow{0}}$

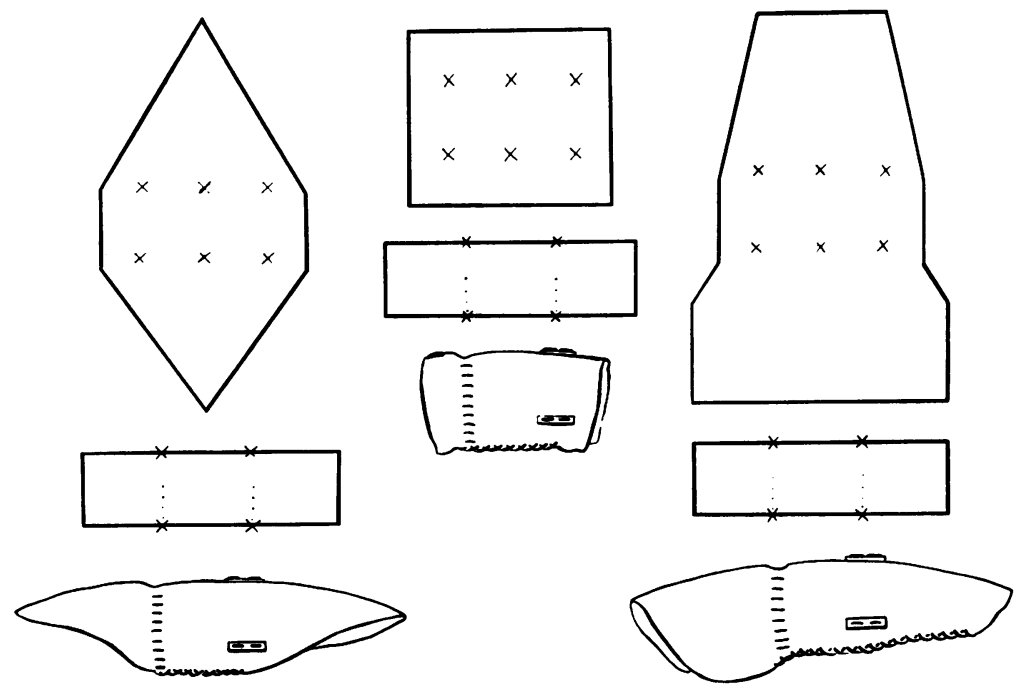

FIG. 1. The shapes of fascia lata strips with commissural marks. Above, the piece for the outer conduit; middle, the strip for the inner three-cusp valve; below, schematic representation of the composite fascial graft. From left, diamondshaped tube; cylinder-type graft; by-pass type graft slightly tapered towards the distal end. The size of the rectangular strip for making the inner valve as well as the commissural marks are identical in all three types of grafts. 

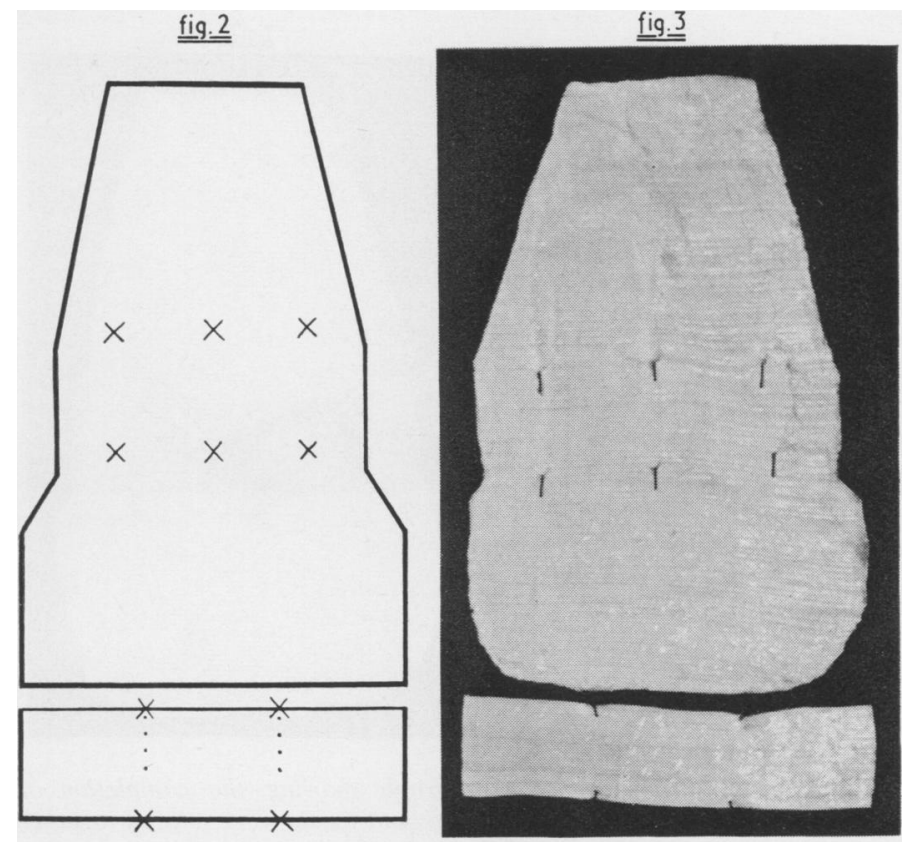

FIGS 2 and 3. Line drawing and photograph of the first step in the preparation of the composite graft. The pieces of fascia lata are cut to size and marked at the commissural points.

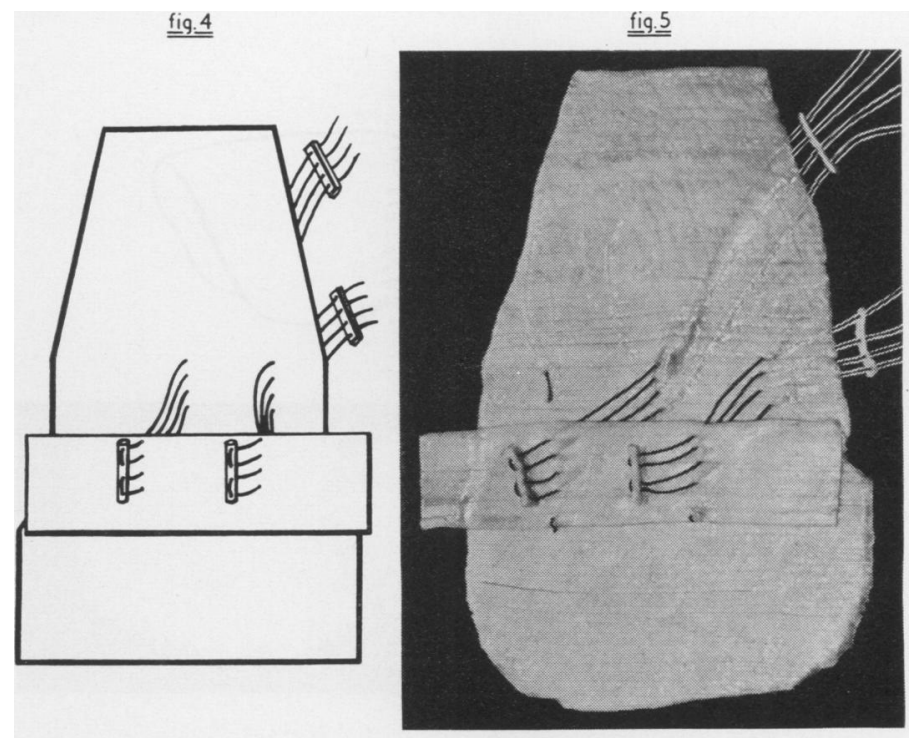

FIGS 4 and 5. Drawing and photograph of the making of the first two commissures. For each commissure, two double needle 4-0 sutures are passed in turn through Teflon lace, valvar strip, outer fascia piece and Teflon patch. 


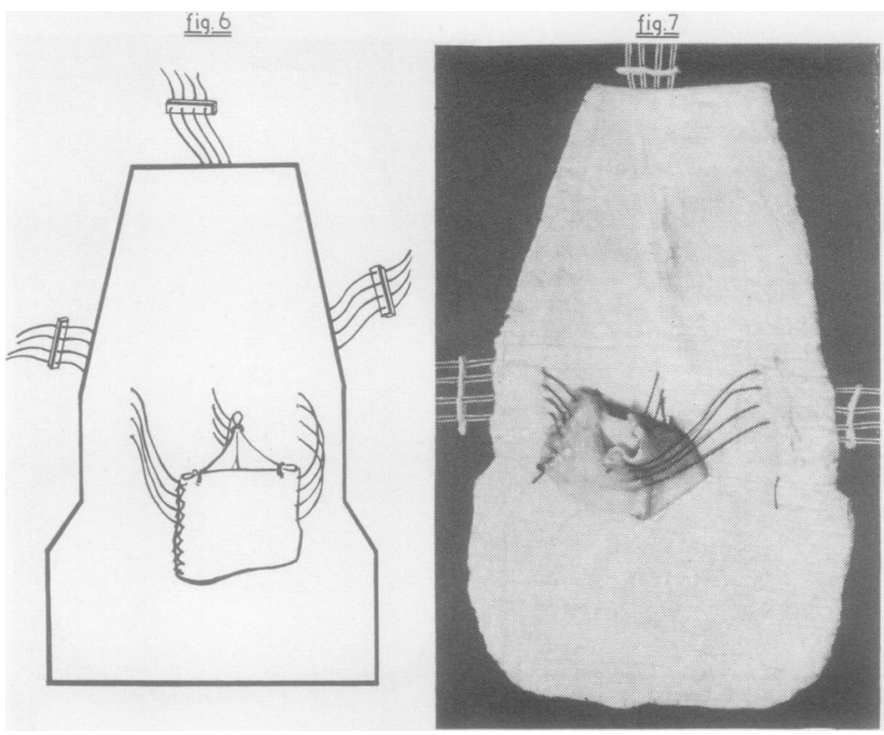

FIGS 6 and 7. Drawing and photograph showing the completion of the valve. The two ends of the inner strip of fascia were sutured together to make a cylinder. The sutures and Teflon patches for the third commissure are placed as previously described and the valve already takes a triangular shape.

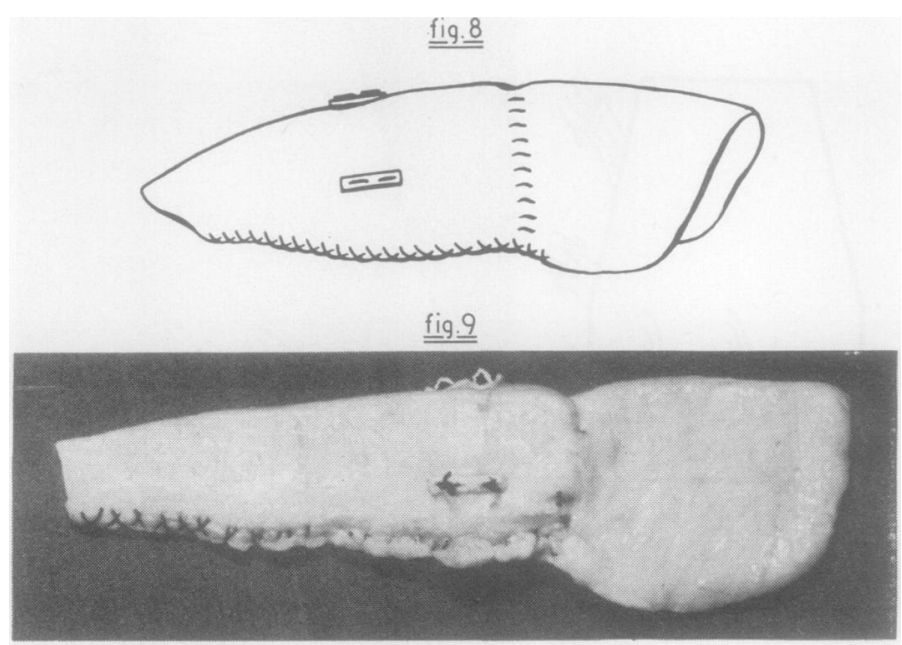

FIGS 8 and 9. Schematic drawing and photograph of the completed fascia lata composite graft. The outer conduit was made by suturing together its two margins. The proximal or lower end of the valve was attached by continuous suture to the outer conduit. The commissural sutures were tied outside the conduit, over Teflon patches. 
ism. Both these parts are made of fascia lata without any supporting frame. On the conduit, the glistening aspect of fascia faces the blood stream while on the valve it makes the concave aspect of the cusps. Three types of composite grafts are used, depending on the anatomy of the case to be repaired. All three are based on the same general principle.

Figure 1 shows the diamond-shaped graft for enlargement of the outflow of the right ventricle; the cylinder type graft adapted for pulmonary valve replacement only; and the bypass graft to be used as a bridge from the anterior wall of the right ventricle to the pulmonary arteries. The making of the bypass-type graft is described.

Immediately after the patient has been anaesthetized a piece of fascia lata is removed from the thigh. Both surfaces of the fascia are carefully trimmed, and fat and loose connective tissue are removed.

The fascia is measured and cut to obtain two pieces, as seen in Figures 2 and 3. The large, slightly tapered piece is to become the conduit containing the three-cusp valve which is made from the small rectangular piece. Fine sutures are used to mark on the fascial strips the com-

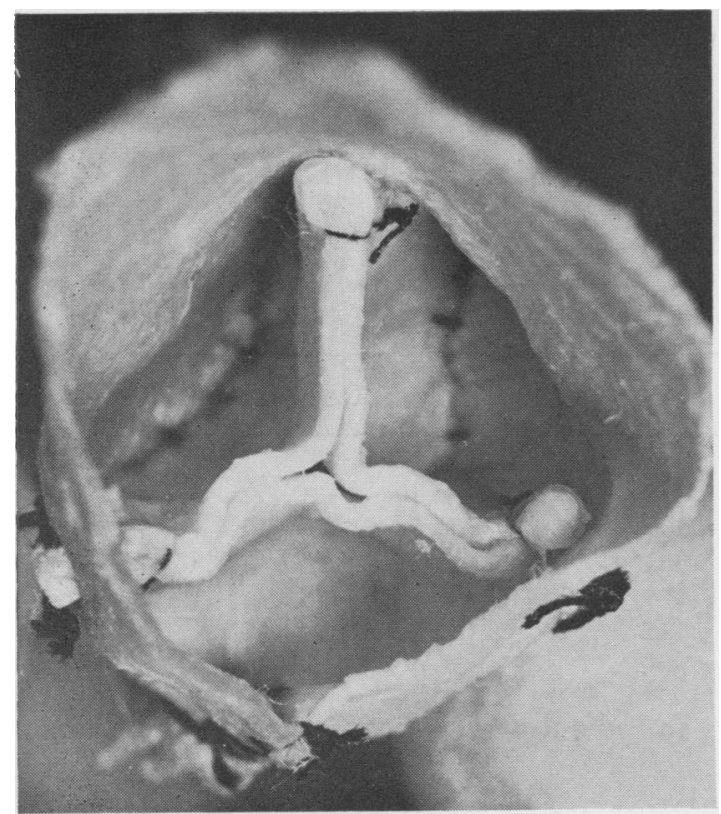

FIG. 10. The graft seen from the distal aspect to show the valve in the closed position. (This graft was fixed in formalin for photographic purposes.)

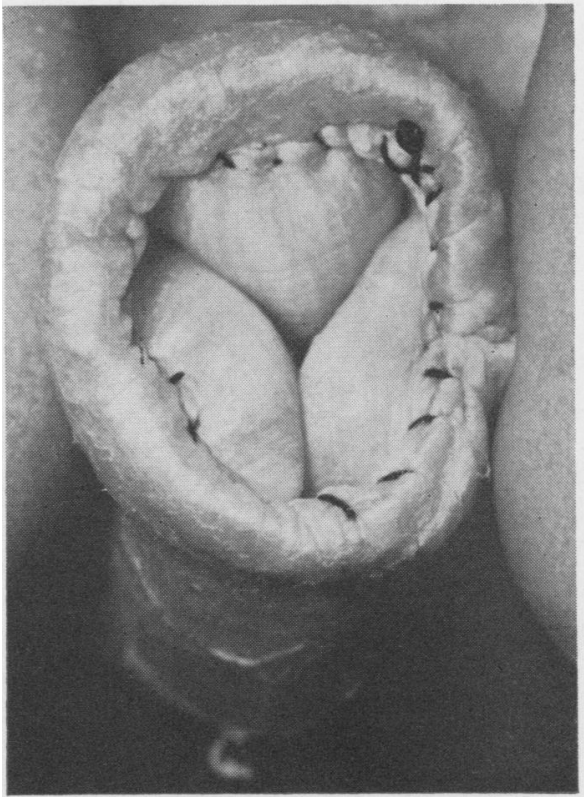

FIG. 11. The graft seen from the proximal aspect to show the three-cusp valve in the closed position. The lower or proximal flap of the conduit was turned up to expose the valve. (This graft was fixed in formalin for photographic purposes.)

missural points. For each commissure two double needle 4-0 sutures are passed through a piece of fine Teflon lace and then in turn through the valvar strip, the conduit strip, and again through a small piece of Teflon fabric. In this way two commissures are prepared as shown in Figures 4 and 5. At this stage the two ends of the valvar strip are sutured together to make it into a cylinder. This suture line becomes the third commissure and it is provided with the same sutures and Teflon patches as the other two commissures.

In order to keep the future valve in a closed position while at rest, a 5.0 suture is placed at the top of each commissure (Figs 6 and 7).

The lateral margins of the large piece of fascia are now sutured together with a double continuous 4-0 stitch starting $2-3 \mathrm{~mm}$. below the level of the base of the valve. This suture is carried upwards towards the tapered end of the conduit as far as required by the anatomy of the particular case in which the graft is to be used.

The commissural sutures are tied outside the conduit over the Teflon patches, and the lower or proximal end of the valve is sutured with a continuous stitch to the conduit. In order to facilitate 


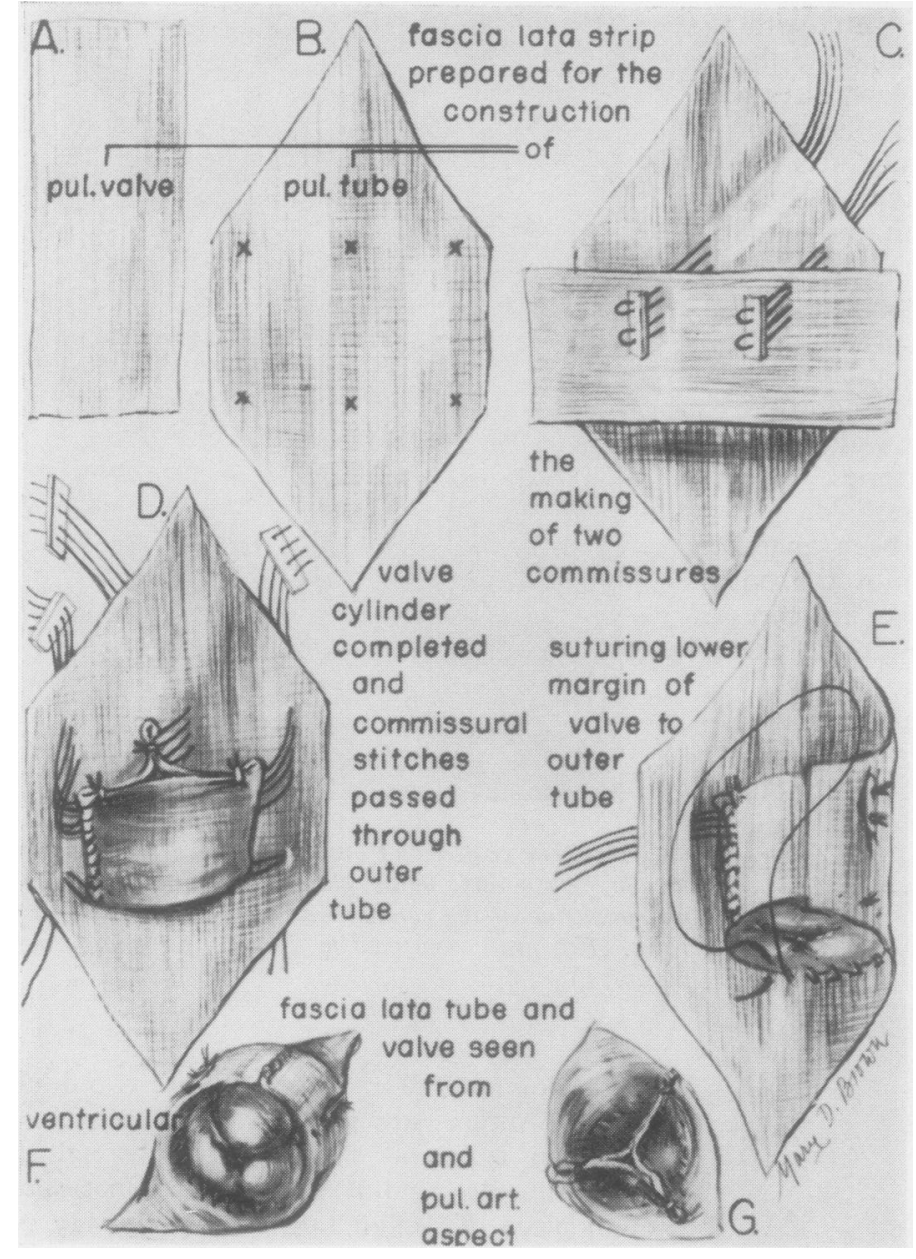

FIG. 12. Artist's view of preparation of diamond-shaped fascia lata composite graft. The making of the graft follows the same steps as for the bypass conduit graft; the only difference is the shape of the outer tube.

ALL SIZES IN $\mathrm{mm}$.
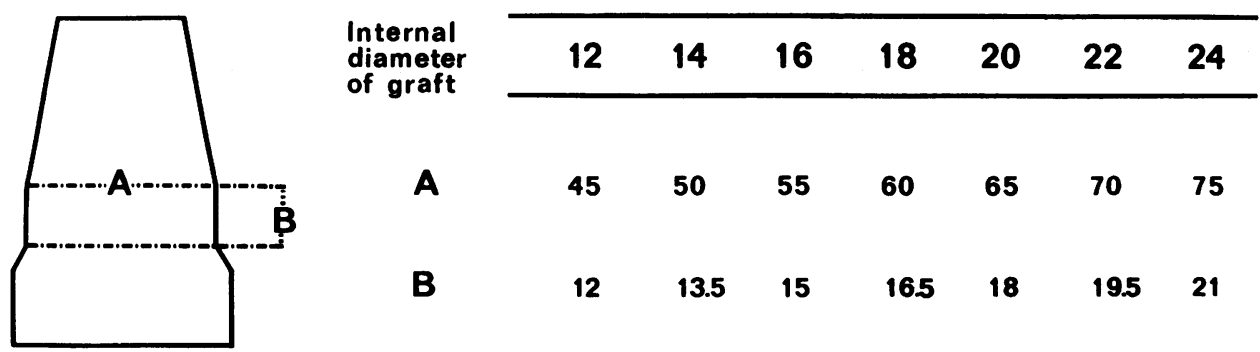

$\begin{array}{llllllll}\text { A } & 45 & 50 & 55 & 60 & 65 & 70 & 75 \\ \text { B } & 12 & 13.5 & 15 & 16.5 & 18 & 19.5 & 21 \\ \text { C } & 55 & 60 & 65 & 70 & 75 & 80 & 85 \\ \text { D } & 12 & 13.5 & 15 & 16.5 & 18 & 19.5 & 21\end{array}$

FIG. 13. Table of sizes to be used for the tailoring of fascial composite grafts ${ }^{1}$.

1Hypodermic Services, Headlands Road, Liversedge, Yorkshire 
this suture three fixation points are made in advance and the lower part of the conduit is turned up as a flap. This suture completes the composite graft (Figs 8, 9, 10 and 11), the ends of which can be tailored by the operating surgeon to adapt the graft to the particular anatomy of the case.

Figure 12 shows the technique of making a diamond-shaped composite graft. Except for the length and shape of the outer conduit, this graft is similar to the bypass-type graft previously described.

The sizes for making composite grafts are shown in Figure 13. The total length of the conduit is estimated, depending on the type of repair to be performed. Usually the amount of fascia available from the thigh is sufficient for a bypasstype graft even in small children.

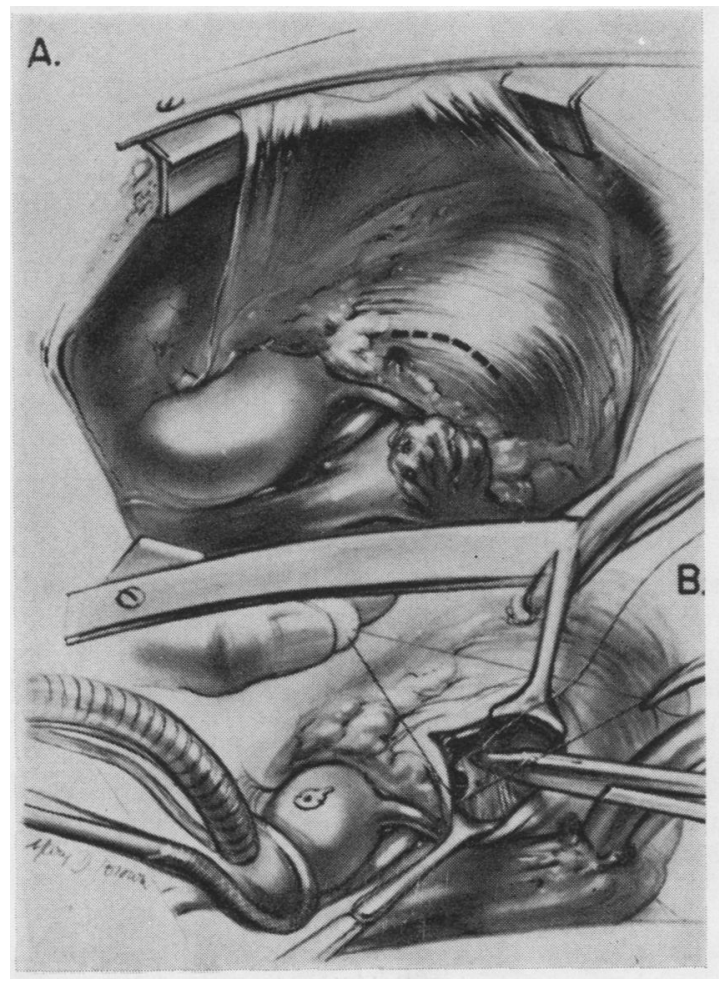

\section{SURGICAL IMPLANTATION OF THE COMPOSITE GRAFT}

The choice between a diamond-shaped and a bypass-type graft depends on the anatomy of the cardiac malformation. When only enlargement of the outflow of the right ventricle is necessary, the diamond-shaped graft is used. For this type of repair a short longitudinal incision is made in the infundibulum of the right ventricle and extended across the pulmonary annulus as far into the pulmonary artery as necessary. When the ventricular septal defect has been dealt with and after the muscular obstruction has been relieved the graft is placed inside the groove made by the longitudinal opening of the right ventricle and pulmonary artery. The graft is sutured distally to the pulmonary artery and proximally to the right ventricle, starting at the posterior aspect of the

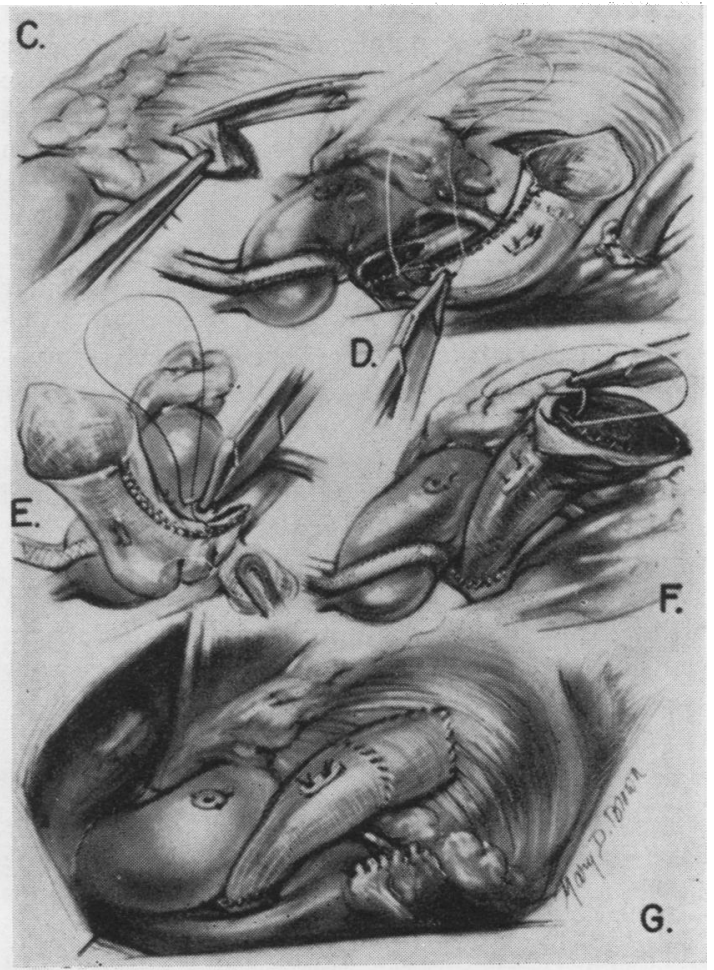

FIG. 14. Artist's view of the surgical repair of corrected transposition with VSD and pulmonary obstruction: A, transversal incision over the right ventricular infundibulum; $B$, patch closure of the ventricular septal defect; $C$, the right ventricular incision is enlarged and given an oval shape; $D$ and $E$, an incision was made over the bifurcation of the pulmonary artery, and the distal end of the graft was sutured to the margins of this incision; $F$, the larger proximal end of the bypass-type graft is sutured to the enlarged opening on the anterior surface of the right ventricle; $G$, the completed repair showing the bypass graft as a bridge over the right coronary artery. 
T A B L E

CONGENITAL HEART ABNORMALITIES WITH RIGHT VENTRICULAR OUTFLOW TRACT AND PULMONARY ARTERY RECONSTRUCTION BY A COMPOSITE FASCIA LATA GRAFT

\begin{tabular}{|c|c|c|c|c|c|c|c|c|c|c|}
\hline & & & $\begin{array}{l}\text { No. of } \\
\text { Cases }\end{array}$ & $\begin{array}{l}\text { Atrial } \\
\text { Septal } \\
\text { Defect }\end{array}$ & $\begin{array}{c}\text { Pulmonary } \\
\text { Hypo- } \\
\text { plasia }\end{array}$ & $\begin{array}{l}\text { Pulmonary } \\
\text { Atresia }\end{array}$ & $\begin{array}{c}\text { Left } \\
\text { Superior } \\
\text { Vena } \\
\text { Cava }\end{array}$ & $\begin{array}{c}\text { Anomalous } \\
\text { Pulmonary } \\
\text { Venous } \\
\text { Drainage }\end{array}$ & $\begin{array}{c}\text { Previous } \\
\text { Shunt }\end{array}$ & Deaths \\
\hline $\begin{array}{l}\text { Fallot's tetralogy } \\
\text { Double outlet right ventricle } \\
\text { Corrected transposition and VSD } \\
\text { Truncus arteriosus II } \\
\text { Fallot's trilogy } \\
\text { Single ventricle and mitral atresia }\end{array}$ & $\begin{array}{l}\cdots \\
\cdots \\
\cdots \\
\cdots \\
\cdots\end{array}$ & $\begin{array}{l}\cdots \\
\cdots \\
\cdots \\
\cdots \\
\cdots\end{array}$ & $\begin{array}{r}12 \\
2 \\
1 \\
1 \\
1 \\
1\end{array}$ & 2 & $\begin{array}{l}8 \\
1 \\
1 \\
1 \\
1\end{array}$ & $\begin{array}{l}4 \\
1\end{array}$ & 1 & 1 & $\begin{array}{r}10 \\
2 \\
1\end{array}$ & 1 \\
\hline Total & . & $\ldots$ & 18 & & & & & & 13 & 2 \\
\hline
\end{tabular}

diamond-shaped tube. This suture restores the continuity between the right ventricle and the pulmonary artery. Two final sutures, on each side of the graft, attach the superficial margin of the cut ventricular muscle to the graft tube and this completes the surgical implantation of the composite graft.

In cases where the diamond-shaped tube cannot be used because of pulmonary atresia (as in some Fallot's tetralogies, truncus arteriosus) or because of the presence of aberrant coronary arteries (as in Fallot's tetralogy, corrected transposition with VSD and pulmonary obstruction) the bypass-type conduit is used.

A transversal incision is made over the infundibulum of the right ventricle and the ventricular septal defect is repaired (Fig. 14 A and B). The pulmonary artery is either opened at its bifurcation (Fallot's tetralogy, corrected transposition) or detached from the aorta (truncus arteriosus) and the fascia lata conduit is attached by its distal end to the pulmonary artery while its wide proximal end is sutured to the enlarged opening in the right ventricle (Fig. $14 \mathrm{C}, \mathrm{D}, \mathrm{E}$, and F).

In this way the bypass conduit curves as a bridge from the infundibular chamber of the right ventricle to the bifurcation of the pulmonary artery (Figs $14 \mathrm{G}$ and 15).

\section{CLINICAL MATERIAL}

Since November 1969, fascia lata composite grafts have been used in 18 patients. As seen from the Table, a variety of congenital heart abnormalities were treated by means of this technique.

The early results are extremely gratifying but the follow-up period is too short to enable us to formulate any conclusions concerning the ultimate fate of fascia lata in the particular haemodynamic environment in which it is placed.

Speculations concerning the propensities of fascial grafts in the low pressure system of the

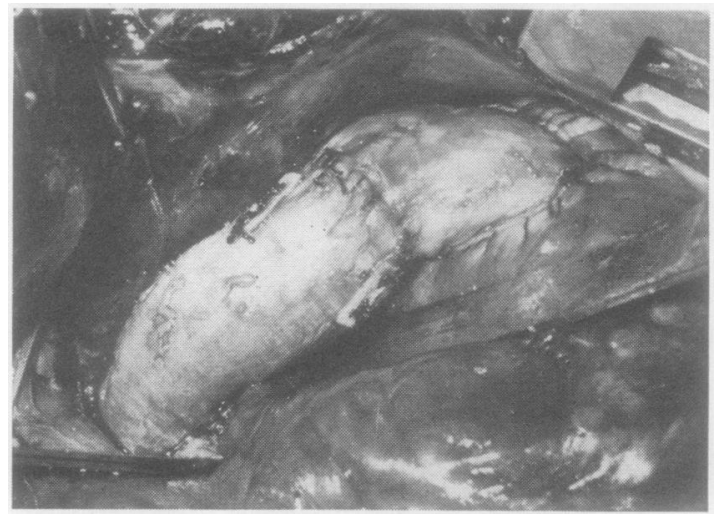

FIG. 15. Operative view of surgical correction of a Fallot's tetralogy with pulmonary atresia and aberrant coronary arteries. The bypass-type graft is seen with its right ventricular attachment and with the distal end curving down towards the bifurcation of the pulmonary artery. The portion containing the valve is not distorted, neither is it compressed in any way.

right heart and the functional implications of pulmonary regurgitation versus pulmonary valve competency together with detailed clinical results are described elsewhere (Ionescu, Ross, Deac, and Wooler, 1970).

We wish to thank Miss Mary D. Brown, medical artist, and Miss Beryl Walsh, from the Department of Medical Photography, for the illustrations.

\section{REFERENCES}

Bowman, F. (1969). Discussion of paper by Wallace, R. B., Rastelli, G. C., Ongley, P. A., Titus, J. L., and McGoon, D. C. Complete repair of truncus arteriosus defects. J. thorac. cardiovasc. Surg., $\mathbf{5 7 , 9 5 .}$

Cooley, D. A., and Hallman, G. L. (1966). Surgical Treatment of Congenital Heart Disease. p. 185. Lea \& Febiger, Philadelphia. Fuller, D. N., Marchand, P., Zion, M. M., and Zwi, S. (1966). Q Homograft replacement of the pulmonary valve. Thorax, 21,

Ionescu, M. I., and Ross, D. N. (1969). Heart-valve replacement with autologous fascia lata. Lancet, 2, 335. 
Deac, R. C., and Wooler, G. H. (1970). Autologous fascia lata composite graft for right ventricular outflow reconstruction in congenital and acquired disease. Thorax, in press. Grimshaw, V. A., Taylor, S. H., Whitaker, W., and Wooler, G. H. (1970). Autologous fascia lata for heart valve replacement. Thorax, $25,46$.

Kouchoukos, N. T., Barcia, A., Bargeron, L. M., and Kirklin, J. W. (1970). Surgical correction of congenital pulmonary atresia with ventricular septal defect. Read before the 50th Annual Meeting of the American Association for Thoracic Surgery, April 8, Washington, D.C.

Lillehei, C. W., Cohen, M., Warden, H. E., Read, R. C., Aust, J. B. DeWall, R. A., and Varco, R. L. (1955). Direct vision intracardiac surgical correction of the tetralogy of Fallot, pentalogy of Fallot, and pulmonary atresia defects. Report of first ten cases. Ann. Surg., 142, 418.

$-\frac{1}{-}$ and Varco, R. L. (1956). Complete anatomical

Levy, M. J., Adams, P and Anderson, R. C. (1964). Corrective surgery for tetralogy of Fallot. J. thorac. cardiovasc. Surg., $48,556$.

Marchand, P. (1967). The use of a cusp-bearing homograft patch to the outflow tract and pulmonary artery in Fallot's tetralogy and pulmonary valvular stenosis. Thorax, 22, 497.

McGoon, D. C., Rastelli, G. C., and Ongley, P. A. (1968). An operation for the correction of truncus arteriosus. J. Amer. med. Ass., 205, 69 .
Rastelli, G. C. (1969). A new approach to 'anatomic' repair of transposition of the great arteries. Mayo Clin. Proc., 44, 1.

- McGoon, D. C., and Wallace, R. B. (1969). Anatomic correction of transposition of the great arteries with ventricular septal defect and subpulmonary stenosis. J. thorac. cardiovasc. Surg., 58, 545.

- Titus, J. L., and McGoon, D. C. (1967). Homograft of ascending aorta and aortic valve as a right ventricular outflow: an experimental approach to the repair of truncus arteriosus. Arch. Surg., 95, 698.

- Wallace, R. B., and Ongley, P. A. (1969). Complete repair of transposition of the great arteries with pulmonary stenosis. A review and report of a case corrected by using a new surgical technique. Circulation, 39, 83.

Ross, D. N., and Somerville, J. (1966). Correction of pulmonary atresia with a homograft aortic valve. Lancet, $2,1446$.

Wallace, R. B. (1969). Discussion of paper by Wallace, R. B., Rastelli, G. C., Ongley, P. A., Titus, J. L., and McGoon, D. C. Complete repair of truncus arteriosus defects. $J$. thorac. cardiovasc. Surg., 57, 95.

_ Rastelli, G. C., Ongley, P. A., Titus, J. L., and McGoon, D. C. (1969). Complete repair of truncus arteriosus defects. J. thorac. cardiovasc. Surg., 57, 95.

Weldon, C. S., Rowe, R. D., and Gott, V. L. (1968). Clinical experience with the use of aortic valve homografts for reconstruction of the pulmonary artery, pulmonary valve, and outflow portion of the right ventricle. Circulation, 37, Suppl. II, p. 51. 